\title{
Possessing epistemic reasons: the role of rational capacities
}

\author{
Schmidt, Eva
}

\begin{abstract}
In this paper, I defend a reasons-first view of epistemic justification, according to which the justification of our beliefs arises entirely in virtue of the epistemic reasons we possess. I remove three obstacles for this view, which result from its presupposition that epistemic reasons have to be possessed by the subject: (1) the problem that reasons-first accounts of justification are necessarily circular; (2) the problem that they cannot give special epistemic significance to perceptual experience; (3) the problem that they have to say that implicit biases provide epistemic. The first problem will be overcome by introducing presentational attitudes that are not in need of justification as basic ways of possessing epistemic reasons. The latter two problems will be solved by introducing epistemic rational capacities of two different kinds, which are exercised in mental states that are ways of possessing epistemic reasons, and by distinguishing these from mental states that are not exercises of epistemic rational capacities.
\end{abstract}

DOI: https://doi.org/10.1007/s11098-017-1025-z

Posted at the Zurich Open Repository and Archive, University of Zurich

ZORA URL: https://doi.org/10.5167/uzh-147526

Journal Article

Accepted Version

Originally published at:

Schmidt, Eva (2019). Possessing epistemic reasons: the role of rational capacities. Philosophical Studies, $176(2): 483-501$.

DOI: https://doi.org/10.1007/s11098-017-1025-z 


\section{Possessing Epistemic Reasons: The Role of Rational Capacities \\ Eva Schmidt}

In this paper, I defend a reasons-first view of epistemic justification, according to which the justification of our beliefs arises entirely in virtue of the epistemic reasons we possess. I remove three obstacles for this view, which result from its presupposition that epistemic reasons have to be possessed by the subject: (1) The problem that reasons-first accounts of justification are necessarily circular; (2) the problem that they cannot give special epistemic significance to perceptual experience; (3) the problem that they have to say that implicit biases provide epistemic reasons. The first problem will be overcome by introducing presentational attitudes that are not in need of justification as basic ways of possessing epistemic reasons. The latter two problems will be solved by introducing epistemic rational capacities of two different kinds, which are exercised in mental states that are ways of possessing epistemic reasons, and by distinguishing these from mental states that are not exercises of epistemic rational capacities.

\section{The Circularity Threat}

Traditionally, epistemologists have focused on the notion of epistemic justification more than on the notion of epistemic reasons. To the uninitiated, this may come as a surprise - in ordinary language, we speak more naturally of believing for reasons than of having justified beliefs. ${ }^{1} \mathrm{I}$ think this situation should be rectified. But what might be the relevance of reasons in epistemology? Here is one plausible role for them: When epistemologists say that a belief is justified, they often hold that this is due to reasons that support it. For instance, the regress problem arises because to justify any belief I have, I have to give a reason that supports it, i.e., cite a further belief, which is then itself in need of justification. This suggests a close connection between epistemic justification and reasons it seems that to justify my beliefs, I have to provide reasons for them.

This intuitive claim is taken up by reasons-first epistemology. On this picture, epistemic justification is to be understood in terms of fit with epistemic reasons. ${ }^{2}$ But plausibly, justification does not arise from any old reasons, but only from reasons possessed by the subject. Here is one way of phrasing this claim:

1 To test my claim, do a google search for these phrases. The search for 'justified belief' and cognates turns up philosophical articles; the search for 'reason to believe' turns up pop songs.

2 What's at stake here is propositional justification - to get to doxastic justification, the belief in question would have to be based on the possessed reasons. 
(Reasons First) That $\mathrm{S}$ has pro tanto justification to believe that $q$ is grounded in the fact that $\mathrm{S}$ possesses an epistemic reason to believe that $q$.

This plausibly entails the biconditional:

$\mathrm{S}$ has pro tanto epistemic justification to believe that $q$ if and only if $\mathrm{S}$ possesses an epistemic reason to believe that $q .^{3}$

(Reasons First) is in need of some clarifications. To begin with, it is a grounding claim. That is, S has justification for her belief in virtue of possessing a reason - her justification is ontologically dependent on her possessed reason. This is how reasons are first, on the picture I propose here. ${ }^{4}$ Next, (Reasons First) is about pro tanto justification. To the extent that $\mathrm{S}$ has at least an epistemic reason to believe that $\mathrm{q}$, she has at least some justification for her belief. One motivation for the claim that there is pro tanto justification is that the reasons that a subject has determine whether she has justification for her belief overall. Plausibly, they do so by contributing pro tanto justification for the belief (or, alternatively, pro tanto justification for suspending or for believing its negation), which in combination gives us its all-things-considered justification. ${ }^{5}$

But what are epistemic reasons? I won't address this topic here; I discuss it in detail elsewhere. (See Schmidt forthcoming) There I argue that epistemic reasons are a kind of normative reasons. I allow that both objective and subjective normative reasons to believe, that is facts and apparent facts that count in favor of adopting a belief, may be at the bottom of epistemic justification. My reasons-first proposal is non-reductive with respect to normativity - the normative status of justification goes back to the normative nature of epistemic reasons.

A final element of (Reasons First) that needs to be clarified is what it takes for us to possess a reason. Apparently, we have to have an attitude of some sort to the reason, but not any old attitude will do. For instance, hopes or desires aren't up for the task, but neither is mere belief. Imagine that I convince myself that I will meet the pope tonight, just for the fun of it. Intuitively, in this case, that I will meet the pope tonight is not a reason I possess to believe that I will meet Jorge Bergoglio

3 The entailment holds given that the biconditional expresses not a conceptual, but at most a metaphysical necessity. For grounding is standardly taken to involve metaphysical necessity. (So, necessarily, if $\mathrm{S}$ has reason to believe that $q$, S has pro tanto justification to believe that $q$.) Moreover, the claim is that all justification can be traced back to reasons. (So, necessarily, if $\mathrm{S}$ has pro tanto justification to believe that $q$, then $\mathrm{S}$ has a reason to believe that $q$.)

4 I don't have the space to give a full argument for the priority claim, but do so in Schmidt (n.d.). A brief statement of my motivation: In other areas, such as philosophy of action, the normative status of actions or attitudes is accounted for by appeal to reasons that count in favor of so acting, or of having the attitude in question. I believe it is theoretically desirable to give a unified theory of the normative status of actions and attitudes including belief in terms of normative reasons. Such a theory further allows us to give an account of what is involved in having propositional justification for belief.

5 Similarly, see Dancy (2004, chapter 2) on contributory oughts. More on this issue below. 
tonight - it cannot justify the latter belief. Rather, it seems that a subject possesses a reason that $p$ only if she justifiably believes that $p$.

Unfortunately, as Bob Beddor (2015) argues, this account is circular: ${ }^{6}$ Epistemic justification is grounded in possessed reasons, according to reasons-first epistemology, but I have just conceded that possession of reasons is grounded in justified belief. But we can't have it both ways: Either possessed reasons are fundamental for justification, or justification is fundamental for possessing reasons.

At this point, we might give up on the project of generally tracing justification back to reasons - at least some beliefs are not justified in virtue of their fit with epistemic reasons. For instance, we might say that some beliefs are justified in virtue of being reliably caused. Or we might say that, by their very nature, all epistemic reasons are possessed reasons: Any mental state is a reason, and the question of what it takes to possess it doesn't even come up. (Beddor criticizes both of these options.)

The alternative response I want to pursue is a foundationalist one. Indeed, a subject possesses a reason that $p$ to believe that $q$ if she has a justified belief that $p$. But this is only one way to possess an epistemic reason. There are other ways to do so with the help of basic presentational attitudes, such as perception, memory, rational intuition, or introspection. ${ }^{7}$ Often, subjects possess a reason that $p$ by having a justified belief that $p$, and this belief is justified thanks to reasons that $q$ and that $r$ that are had via further justified beliefs that $q$ and that $r$. For instance, that my parents will visit me this weekend is a reason I possess, by way of justifiably believing that my parents will visit me this weekend. I justifiably believe this in virtue of justifiably believing, one, that over the past few months my parents have visited me every weekend, and two, that my mother told me over the phone that they would do so again this weekend. But these latter beliefs are justified for me not in virtue of my having any further beliefs, but in virtue of my remembering, one, that my parents have visited me regularly in the past, and two, that my mother told me over the phone they would visit. So now, we have to come to a different kind of presentational attitude - memory - that constitutes my possession of the most fundamental reasons in the chain (that over the past few months my

6 Beddor's concern is evidence, not epistemic reasons. I transfer his argument to epistemic reasons. Why not stick with evidence? Again, setting things up in terms of reasons puts a promising unified picture of actions and attitudes (including belief) and their normative status in our reach. Additionally, reasons talk makes room for the possibility that the fact that $p$ itself may be a normative reason to believe that $p$, where this seems problematic when we conceive of that $p$ as evidence that $p$. So the reasons-first view can give an account of apparently groundless belief that is unavailable to the evidence-first view; it is not just a notational variant of the latter. Thanks to an anonymous reviewer for pressing me on this point. Also cf. my (2017).

7 The term "presentational attitude" is from Schroeder (2011). 
parents have visited me every weekend and that my mother told me that they would visit me again this weekend). This basic presentational attitude is not itself in need of justification. ${ }^{8}$

This resolves the circularity threat. At some point, the subject's possession of epistemic reasons bottoms out in mental states that don't require epistemic justification themselves, about whose justification it is inappropriate to worry. The question: 'What justifies your memory that your parents told you that they would visit you this weekend?' for instance, is misguided. A particular memory is not something that I can be rational or irrational in having, or be blamed for having or not having. It's just something that I find myself with. This is part of the role in my cognitive life that is characteristic of the capacity of memory. Unlike belief, I can't acquire or revise my memories in response to epistemic reasons to remember, which I possess. What I remember or don't remember is not under my rational control in this way. So my possession of reasons by remembering can be explained without appeal to further justification.

Which mental states are included in the class of basic presentational attitudes? First, they have to be a kind of attitude to which, as described, notions such as is justified, ought to, or is irrational cannot be applied. Second, like belief, they have to have a mind-to-world direction of fit. (See Anscombe 1963.) That is to say, they have to present the world to the subject as being a certain way, such that they are mistaken if the world is not as they purport. ${ }^{9}$ One motivation for this restriction is that I am giving an account of epistemic justification. For this we want truth-related reasons and ways of possessing such reasons that are geared towards achieving knowledge, rather than, say, wishful thinking. These restrictions exclude desires as basic presentational attitudes because they have the wrong direction of fit. Third, to be ways of possessing epistemic reasons, basic presentational attitudes, just like belief, have to be available for deliberation. In some minimal sense at least, the subject has to be able to register that she possesses a reason to believe by having the attitude. (More on this below.)

The understanding of the possession of epistemic reasons that can be extracted from this line of thought works similarly to a recursive definition:

(Possessed Reasons) S possesses an epistemic reason that $p$ to believe that $q$ if and only if (1) that $p$ is an epistemic reason to believe that $q$, and (2) $\mathrm{S}$ justifiably believes that $p$ or $\mathrm{S}$ has a

8 Philosophers distinguish episodic memories and propositional memories. Assume that in the example, I have direct, experience-like (i.e., episodic) memories of all those times my parents visited me and of their telling me they'll come again this weekend.

9 I take this to exclude imagining and supposing, which, as Anscombe $(1963,4)$ might say, are not "impugned" if they don't match the facts. To the extent that some emotions have a mind-to-world direction of fit, they are included in the presentational attitudes. 
basic presentational attitude that is not in need of justification (a PANINI) with the content that $p .^{10}$

Beddor $(2015,1862 / 3)$ objects to this approach as well. He argues that, if it is correct, then two subjects who have the same memories (or the same experiences, in Beddor's own example) will in all cases possess the same reasons to believe, and thus the same propositional justification for their beliefs. But there are counterexamples to this claim, which involve defeaters. Imagine that I have an (almost) duplicate who has the same memories as I have, but who, additionally, has just heard that her father had to go to the hospital because of a serious illness. Plausibly, because of this rebutting defeater, her belief that her parents will come to visit her this weekend is not propositionally justified even though we possess the same reasons in virtue of what we remember.

Undercutting defeaters pose a slightly different challenge: Imagine that my duplicate forms the belief that her phone line was faulty (so that she misunderstood her mother, who really told her that her parents would not come by this weekend). It seems that in light of this defeater had by my duplicate, the phone call from her mother ceases to be a reason for her to believe that her parents will come by altogether. (Cf. Dancy (2004)) It appears that my duplicate and I have the same PANINIs, but we possess different reasons and thus different justification for our respective beliefs about our parents' visits. In light of these counterexamples involving rebutting and undercutting defeat, (Possessed Reasons) and (Reasons First) should be abandoned, says Beddor.

I have two responses to this. First, undercutting defeat. That, as my duplicate remembers, her mother told her over the phone that her parents would come visit this weekend is not a reason at all for her to believe that her parents will visit her. But that my mother told me that my parents would visit me is a reason for me to believe that they will. So, (Possessed Reasons) gives the result that I possess a reason to believe so and my duplicate does not - for in my case, but not in hers, condition (1) is met. The case is not a counterexample to my proposal, then.

Second, the supposed counterexample involving rebutting defeat can be neutralized if we take seriously the distinction between pro tanto reasons and all-things-considered reasons. We can say that, in virtue of our memories, both me and my duplicate have some reason to believe that our respective parents will come to visit this weekend. Both of us thereby have pro tanto justification some justification - to believe that our parents will come to visit, in virtue of what we remember. By contrast, our all-things-considered reasons include everything that we believe, remember,

10 (Possessed Reasons) is supposed to be neutral between the factoring account and Schroeder's (2008) two-relations account, for that $p$ is not required to be a fact, but may also be a state of affairs.

The acronym "PANINI" alludes to the, originally Italian, word "panino", referring to sandwiches or bread rolls. Since my "PANINI" is the singular form, I will unfortunately have to ignore the qualms of linguistically sensitive readers and use "PANINIs" as the plural form. 
experience, etc. With regard to them, there is a difference between me and my duplicate, but it is accompanied by a difference in our overall mental states, for she has a belief and a PANINI that I lack, viz. the belief and auditory experience concerning her father's sickness. Given all of the reasons possessed by my duplicate, her belief that her parents will come to visit her is not all-thingsconsidered justified, even though my corresponding belief is. But this is no problem for my account, for we also differ with respect to our all-things-considered possessed reasons and with respect to our whole body of PANINIs and beliefs. ${ }^{11}$

So far so good. Unfortunately, my reasons-first view faces two further, interrelated problems. The first of them - the epistemic significance problem - has been raised by Byrne (2016): Despite what I've just argued about PANINIs, my view can't make sense of the special epistemic significance of perceptual experience. The second - the implicit bias problem - comes from Kornblith (2015). ${ }^{12}$ The presented view can't draw a principled distinction between implicit biases and PANINIs and so entails that implicit biases are basic ways of having epistemic reasons. Let me introduce these problems next.

\section{The Epistemic Significance Problem and the Implicit Bias Problem}

To get clear on the epistemic significance problem, let's turn from memory to visual experience, particularly to the experiences of superblindsighters. Their cognitive systems skip the step in which normal-sighted subjects have a conscious experience as if $p$, and move directly from subpersonal

11 But don't we first have to figure out which of our beliefs are (all things considered) justified before we can make any definite claims about whether any of them constitute possession of an epistemic reason? (Beddor, 2016) Here, my answer is that PANINIs are ways of possessing reasons simpliciter. If that $p$ is a reason for a subject to believe that $q$ and she has a PANINI with the content that $p$, then she possesses this reason. From this starting point, the belief that $q$ will be pro tanto justified for her, so she will, in this light, also possess that $q$ as a reason via her belief. If, however, her reason that $p$ is rebutted by another reason she has, then she does not have all-things-considered justification for her belief that $q$. So, in light of her whole body of PANINIs and beliefs, she doesn't have that $q$ as a reason either. Depending on whether the belief that constitutes possession of the reason in question is pro tanto or all-things-considered justified, then, it will constitute mere pro tanto or all-things-considered possession. Again, though, what determines whether the subject has reason or justification for any of her beliefs is what PANINIs she has; as long as the content of a PANINI is indeed a reason, the subject has this reason. All possession of reasons, no matter whether pro tanto or all-things-considered, will in the end have to be cashed out by reference to the PANINIs backing it, whose status as ways of possessing reasons simpliciter is prior to any question of justification.

12 I've adapted Kornblith's problem to my purposes. His objection concerns only constitutivist view of epistemic reasons. 
processing of the information that $p$ to the belief that $p .{ }^{13}$ Byrne claims that proponents of reasonsfirst views like mine have to say that a superblindsighter's belief is as well justified as the corresponding beliefs of a normal-sighted subject. So, experience as if $p$ doesn't give us anything extra, epistemically speaking, that we would be missing otherwise. ${ }^{14}$ More generally, Byrne's claim is that, on reasons-first views, the subject's subpersonal processing all by itself can put her in a position immediately and justifiably to believe that $p$. For, plausibly, what matters for justification is that the subject have a world-directed mental state with the right causal history. But then why shouldn't a belief do the job just as well as an experience? What do PANINIs more generally bring to the table that isn't taken care of by belief backed by the right kind of subpersonal processing? Byrne's argument touches on my view in the following way. I have argued in the previous section that proponents of a reasons-first view need to appeal to attitudes other than belief, the PANINIs, so as to avoid Beddor's circularity threat. Byrne's argument suggests that this is not true. Rather, my view has the consequence that reliably caused belief itself can be a PANINI in which possession of epistemic reasons bottoms out. Our basic grasp of epistemic reasons can be fully accounted for in terms of the externalist notion of reliability. This not only - firstly - forces me to abandon the reasons-first program. It also - secondly - shows that reasons-first views are committed to denying the undeniable significance of perceptual experience for justifying empirical belief (and the same goes for episodic memory and other non-doxastic presentational attitudes). We have to conclude that the reasons-first view sketched above is incorrect.

One way to deal with this objection is to bite the bullet concerning the second claim, while arguing that the first claim is incorrect. We could say that there is no need to appeal to non-doxastic presentational attitudes to account for possession of reasons, all we need is belief. Now it might seem that it is impossible to make this move. An appeal to reliability certainly threatens the reasonsfirst view, as Beddor $(2015,1863)$ argues, for it raises the question why we should not become allout reliabilists in the first place. That is, we might as well ground justification in reliability without putting in the extra element of epistemic reasons. Contrary to appearances, however, reasons-first epistemologists can say that reasons are only ever possessed via belief, by endorsing a low bar view of reason possession, as suggested by Schroeder (2011). The resulting view states that mere belief is

13 Real subjects afflicted with blindsight have a blind spot in their visual fields, but are able to guess reliably, for some things present in their blind spot, what is there. The imaginary superblindsighters form genuine beliefs in direct response to visual processing that never leads to conscious visual experience.

14 To be precise, Byrne makes this claim for a much broader family of epistemological views, even including standard reliabilist views. I apply his challenge to reasons-first views here. 
sufficient for possessing epistemic reasons. ${ }^{15}$ In other words, we don't have to appeal to reliability, but neither do we have to concede that having reasons requires justified belief. This proposal answers Byrne's challenge by biting the bullet, but also resolves the circularity threat by denying that possession of reasons is grounded in justified belief. ${ }^{16}$

An apparent problem of the proposal is that on it, any crazy belief (like my belief about the pope) will constitute possession of an epistemic reason and thus be able to contribute to the justification of other beliefs. Schroeder $(2011,210)$ gives an argument that this problem does not arise, which can be summarized as follows: Imagine that a subject believes that $p$ and thus possesses that $p$ as a reason. Let's ask ourselves whether that $p$ can then add to the propositional justification of the belief that $q$. Say that the subject's belief that $p$ is itself not propositionally justified; she has no sufficient reason to believe that $p$, but does so anyway. In this situation, she automatically has conclusive reason not to believe that $p$, and so not to use that $p$ in her reasoning with regard to $q .{ }^{17}$ But if this is the case, her belief that $p$ can't have any bearing on the justification of her belief that $q$. So, if the belief that $p$ is not itself propositionally justified, it automatically can't make a difference to the justification of the belief that $q$, even though in believing that $p$, the subject indeed possesses that $p$ as an epistemic reason.

The basic idea of the argument is that any belief that $p$ that a subject has will already be propositionally justified or unjustified, by virtue of how it fits with the subject's other beliefs. If the belief that $p$ is unjustified, this will be either because she has no reason to endorse that $p$ or because she has reasons against endorsing it. Either way, it's already a given that it would be irrational to

15 On Schroeder's own low bar view, non-doxastic presentational attitudes are also ways to possess reasons. However, what is relevant to my discussion is a view that limits attitudes that constitute reasons possession to mere belief.

16 Another reaction to the superblindsighter case would be to claim that her subpersonal states that lead to her perceptual belief count as ways of possessing reasons. This reaction leaves the second problem raised by Byrne in place. Additionally, as suggested above, a subject cannot possess a reason by means of an unconscious and introspectively inaccessible subpersonal state. After all, it is the subject who is said to possess the reason, and how can that be the case if there's not even a blip on her radar indicating to her that she does? We further get the problem of which subpersonal states count as possessing a reason and which don't: For instance, it seems that I don't possess an epistemic reason in virtue of the stimulation of my retina by light waves, but this is no less a subpersonal presentational state of mine than the subpersonal state preceding my perceptual belief. Thanks to Daniel Star for raising this issue.

17 Why accept that $\mathrm{S}$ here has conclusive reason not believe that $p$ ? According to Schroeder $(2011,210)$, not having sufficient reason to believe that $p$ just $i s$ having conclusive reason not to believe that $p$. Think about it this way: If I have no reason, or barely any reason to believe that something is the case, I had better not form any positive belief on the issue. $\mathrm{S}$ then has conclusive reason not to believe that $p$ in virtue of the insufficiency of the reasons she has to believe that $p$. 
appeal to the belief that $p$ in reasoning, and so, that although having the belief is a way of having the reason, it cannot bear on what else the subject is justified to believe.

Think of it in terms of BonJour's (1980) clairvoyant cases: What makes it the case that Norman's belief that the president is in New York can't be used to justify further beliefs of his? It's that Norman either has a reason to believe that he has no clairvoyant abilities or that he has no reason to believe that he has clairvoyant abilities. Even in the second case, where there are no other reasons that Norman has which count against his clairvoyant ability, the lack of reasons alone is sufficient to block, as an undercutting defeater, the justificatory force of the belief (and of the reason possessed by way of it) with respect to further beliefs. This is the case, according to the low bar view, despite the fact that having the belief that the president is in New York is a way of possessing a reason to adopt further beliefs.

Even though the low bar view is an interesting way of responding to the problem of the epistemic significance of experience and the circularity threat, I am not convinced by it. This is where we have to turn to the implicit bias problem.

Here is a counterexample to the low bar view. ${ }^{18}$ Sam is a member of his department's search committee. He reviews several applications for the professor position to be filled, among them applications sent in by Louise and Ludwig. As a matter of fact, the quality of Louise's and Ludwig's applications is exactly the same - they are both equally well qualified for the job. Unfortunately, Sam is afflicted by implicit biases against women, including the bias that women generally are not well-suited to be professors. Because of his implicit bias, he forms the belief that Ludwig is more qualified for the position than Louise. (Cf. Steinpreis et al. 1999.) Additionally, Sam post hoc rationalizes his implicit-bias driven judgment. He focuses on features of Louise's application that count against her getting the job and forms the corresponding beliefs, whereas he passes over the negative features of Ludwig's application without paying attention to them or forming the corresponding beliefs. Sam is not aware of his bias and thinks of himself as someone who forms accurate judgments about the candidates. To sum up, Sam has accurate visual experiences of what is written in the applications, but his implicit bias initially leads him to disregard the evidence of his senses and so to believe that Ludwig is more qualified than Louise. Moreover, by guiding his attention to certain features of the applications, it leads him to come up, after having formed this belief, with matching rationalizing beliefs about the qualities of Ludwig's application and the lack thereof with respect to Louise's application.

The overall result is that Sam, in believing that Ludwig is more qualified for the position than Louise, not only possesses an epistemic reason, but that his belief is also propositionally justified. It

18 Adapted from Kornblith (2015). Relatedly, see Siegel (2013) on anti-selection of experience for uptake. 
fits with his perception-based post hoc beliefs about Louise's and Ludwig's applications; these beliefs provide sufficient reason for him to believe that Ludwig is more qualified than Louise, so it is not the case that Sam has conclusive reason not to believe so. We have to concede that his belief is a way for Sam to have a reason and that its justificatory strength with regard to further beliefs is not defeated by lack of support. So for instance, Sam has propositional justification for his belief that the department shouldn't hire Louise thanks to the reason he possesses by believing that Ludwig is more qualified for the position than Louise. ${ }^{19}$

This consequence of the low bar view is just not plausible. When implicit biases cause us to have corresponding beliefs that are not borne out by the available facts, the beliefs are clearly not justified. In the example, given that Louise and Ludwig sent in applications of exactly the same quality, which Sam has studied, it has to be the case, one, that his belief - that Ludwig is more qualified than Louise - is itself unjustified and, two, that the belief cannot contribute to the propositional justification of further beliefs. Since the low bar view can't account for this, we have to look for another reasons-first view, a view that will give the right results with respect to implicit bias cases. ${ }^{20}$ With this, let's turn to my own solution of the epistemic significance problem and of the implicit bias problem.

\section{How to Solve the Problems: The Epistemic Significance of Perceptual Experience}

I have argued that a low-bar response to the epistemic significance problem leads to trouble because it is afflicted by the implicit bias problem. So let me provide my own response to the epistemic significance challenge, which upholds both (Reasons First) and (Possessed Reasons). It tries to preserve the special epistemic relevance of perceptual experience and thus denies that the

19 An anonymous reviewer suggests that the low bar theorist might try to appeal to reliabilism to respond to my objection. For instance, she might say that $\mathrm{S}$ possesses a reason in believing that $p$ only if this belief is reliably caused. (See Goldman 2011.) In the example, Sam's post-hoc beliefs are not reliably caused, for their production is guided by his bias. While this is a departure from the low bar view, it is certainly an available option.

However, I don't think this option should be attractive for proponents of a reasons-first view. As I mentioned when first introducing the low bar view, Beddor points out that, if we go this way, it is not clear how it can be argued that possessed reasons are fundamental to justification, not vice versa. That is, one might equally well hold that justification is grounded in reliability immediately, and possession of reasons is grounded in justified beliefs.

20 This argument doesn't immediately affect Schroeder's original low bar view, since he includes non-doxastic presentational attitudes as ways of possessing reasons. However, if we strengthen the example by including that Sam's perceptual experience of the applications is also warped, for instance in virtue of selection bias or cognitive penetration, Schroeder's view is in trouble. For then Sam's doxastic and non-doxastic presentational attitudes taken together constitute possession of undefeated reasons to believe that Ludwig is more qualified for the job than Louise. 
superblindsighter's belief is justified, but in a principled, non-ad hoc way. Note that I will not pursue a solution of the problem that appeals to the presentational phenomenal character of perceptual experience. Byrne discounts such solutions by pointing out that (in my terms) mental states without phenomenal character can also be basic ways of having reasons, which can then contribute to the justification of other beliefs. Further, if what matters is the assertoric force of perceptual experience, which is somehow intertwined with its phenomenal character, it is unclear why the assertoric force of belief can't do the same job all by itself.

My response to the epistemic significance problem makes use of my reply to the circularity threat. What is special about perceptual experience is precisely that it is a PANINI, just like memory. It is able to provide fundamental access to epistemic reasons for beliefs about our present environment. As before, the question: 'What justifies your visual experience as of $p$ ?' is inappropriate; an experience is not something that I can be rational or irrational to be undergoing, nor can I be blamed for undergoing it. It just happens to me. This is part of the role that experience (and PANINIs generally) characteristically plays in our mental lives. By contrast, belief is a kind of mental state about whose justification one can worry. It can be rational or irrational to have a belief, and a subject can be blamed if she believes against what her epistemic reasons indicate. We can, and should, update our beliefs in response to epistemic reasons we possess. ${ }^{21}$ Here, again, it is important that subjects are conscious of what reasons they possess - otherwise, they could not be required to revise their beliefs in response to their reasons.

The result of this difference between belief and PANINIs is this: If my belief that $p$, which results directly from subpersonal processing, is taken to constitute my basic possession of the epistemic reason that $p$, its quality as a way of possessing the reason is thereby not fixed. Assume that it is a fact that $p$, so that it is a de facto good epistemic strategy to use the belief that $p$ in further reasoning. Still, while we are talking about mere belief, it is - from my perspective - not settled whether I just stumbled upon a fact by guessing randomly, say, or whether I am genuinely in possession of an epistemic reason in believing as I do. This problem is overcome as soon as the belief is itself a rational response to reasons already possessed by me - in that case, my belief is an exercise of my epistemic rational capacities and so I genuinely possess a reason.

21 Does this characterization fit for perceptual belief? Imagine I am wearing high-end virtual reality glasses and it looks to me just like I'm under water, facing a manta ray, even though (I know that) I'm in my living room, which contains no marine life. Can I really shake the belief that there's water around me or that there's a manta ray? It may seem that my basic perceptual beliefs are gut-reactions that I cannot revise in response to reasons I possess. One plausible reply here is to appeal to Gendler's (2008) distinction between alief and belief: I have aliefs about the water and the manta ray that are not reasons-responsive, but I am indeed able to refrain from believing that I am under water facing a manta ray, because I know that I'm not. 
But why do PANINIs and beliefs differ with respect to whether they are in need of justification? The role of believing in our cognitive lives is that of being a rational response to epistemic reasons we already possess. We form beliefs by deliberating on (or at least responding to) how the facts present themselves to us; as a minimum, this means that we have some immediate awareness as to the source of our beliefs, as when I know from memory that twelve squared is $144 .^{22}$ Whether a belief is genuinely a way of possessing a reason is in part determined by whether the prior presentational states it is a response to are ways of possessing epistemic reasons. By contrast, the role of PANINIs is to be a rational response to otherwise unpossessed epistemic reasons, since it is their job to bring epistemic reasons into our possession in the first place. Whether they are genuinely ways of possessing epistemic reasons therefore cannot be determined by whether prior presentational states are ways of possessing reasons.

Let me illustrate this with the superblindsighter's belief about what is going on in her blind field. This belief just pops into her head, she has neither an immediate awareness of its source nor a prior conscious state presenting her with what is the case. So for her, whether her belief has anything to do with the facts, i.e., whether it is genuinely a way of possessing an epistemic reason, is completely up in the air. It is not a rational response to possessed epistemic reasons, but an immediate effect of subpersonal processes, which don't involve any epistemic reasons possessed by the subject. Since her belief doesn't play the role it should in our cognitive lives - of being a rational response to possessed reasons - it is not a way of possessing an epistemic reason. Against this backdrop, it is easy to see the epistemic significance of perceptual experience: Since perceptual experience and the other PANINIs are basic rational responses to unpossessed reasons, whether they are ways of possessing reasons does not depend on prior possessed reasons. So we can just take them as starting points in our reasoning without putting in the extra work of trying to justify them. $^{23}$

22 This goes for remembering, intuiting, etc. that $p$ generally, in cases where there is no conscious non-doxastic attitude that comes before the subject's believing from memory, intuitively, etc. that $p$. In these cases, the subject is introspectively aware at least of the source of her belief, and able to understand her believing as a rational response to memory, intuition, etc., which in turn are her rational capacities to take up unpossessed reasons. This doesn't require her to have a prior fully conscious mental state of remembering, intuiting, etc. that $p$. It does plausibly involve a preceding mental state that has the epistemic reason as its content, of which the subject is minimally conscious. For this is the best explanation of why she doesn't know just about anything from memory, by intuition, etc., but comes to possess very specific epistemic reasons from these sources. As I will argue below, not even this much is given in the cases of superblindsight and implicit bias.

23 This is compatible with conceding that these possessed reasons can be defeated, for instance when I learn that I have taken drugs which cause hallucinations. 
So when I see that there is a pink pig, for instance, I am in possession of the reason there is a pink pig simply by having the experience. I can reason from it to beliefs about the pig. My superblindsighter duplicate, by contrast, does not possess the reason there is a pink pig simply by believing that there is a pink pig - she would still have to establish that this belief is a rational response to prior possessed reasons. So she cannot take her belief as a starting point of reasoning, but I can. That is the epistemic significance of perceptual experience (and similar things can be argued for the other PANINIs). ${ }^{24}$

\section{How to Solve the Problems: Implicit Bias}

Unfortunately, this cannot be the whole story. For if we now turn to the implicit bias problem, we see that the situation is a bit more complicated. Sam's belief that Ludwig is better qualified for the job than Louise is partly based on his perceptual experience of looking at their applications. But his negative judgment of Louise's qualities has its source in his implicit bias that women generally are not well-suited to be professors. The problem is this: Social psychologists point out that implicit attitudes enable agents to react quickly, and often appropriately, to novel situations. With the help of implicit attitudes, agents can categorize new things they encounter in familiar ways. This enables them to have immediate expectations of these new things and to respond to them accordingly. Their advantageousness explains why humans have implicit attitudes, including implicit biases. So,

If, on the other hand, we conceive of the superblindsighter as having immediate awareness that the source of her belief is what is in front of her, I think we should say that her belief is a way of possessing a reason. I would then classify the (subpersonal?) state or process in virtue of which she is aware of the source of her belief as the relevant PANINI. But this is not how the superblindsighter is typically conceived.

This account is similar to that defended by Sylvan and Sosa (forthcoming), and I am sympathetic to much of what they say. However, as I will argue at the end of this article, I disagree with their claim that epistemic competence is more fundamental than reasons. Further, as I understand them, they think that justified belief gets its positive status partly from fit with epistemic reasons, but that epistemic reasons play no role in determining the epistemic standing of "attractions to assent" (PANINIs). By contrast, I hold that beliefs and PANINIs both are ways of possessing reasons in virtue of being appropriate responses to epistemic reasons, the only difference being whether these are possessed or unpossessed reasons.

24 But what about the intuition shared by philosophers such as Byrne or Block (1995) that the superblindsighter's belief is justified? How is my claim not an ad hoc denial of the intuition? On the one hand, I have tried to show that there is good reason to reject it. From the superblindsighter's perspective, her visual belief is completely arbitrary and still in need of justification; we should agree with her. On the other hand, it seems to me that my opponents and I are at an impasse involving internalist and externalist intuitions (where I have tried to support the internalist side, whereas my opponents point to the intuition that reliability is enough for the superblindsighter to have justification). In light of this, I don't believe that intuitions alone can carry much weight here when it comes to deciding the debate. I say more on this issue in my (n.d.). 
implicit biases are rational from an evolutionary or survival-oriented standpoint and this may be sufficient for them to exhibit epistemic rationality. ${ }^{25}$

So, maybe implicit biases are a kind of PANINIs, too, just like memory or experience, and it is their function in our cognitive lives to be fundamental ways of possessing epistemic reasons. If so, (Reasons First) and (Possessed Reasons) commit us to saying that Sam's belief is justified, and that in having this belief, Sam possesses a reason that can contribute to the justification of further beliefs. This implausible consequence should be avoided.

Coming from the opposite direction, the worry is this: Why should the fact that, thanks to their role in our cognitive lives, we cannot say of the PANINIs that they are justified or unjustified, make any difference for epistemology? ${ }^{26}$ Just because there can be no question of their justification it doesn't follow that remembering or seeing that $p$, for instance, have any more epistemic significance than merely believing that $p$. This can be highlighted by pointing to the fact that implicit biases (which seem to be basic, unjustifiable responses to the environment as well) don't have any special epistemic significance either.

The reasons-first theorist, then, needs to find (1) a way to draw a principled line between PANINIs, on the one hand, and beliefs, on the other, while (2) excluding implicit biases as basic ways of possessing epistemic reasons. To do so, I again draw on the distinction introduced above between attitudes that are rational responses to unpossessed epistemic reasons and those that are rational responses to possessed epistemic reasons: PANINIs are exercises of epistemic rational capacities, namely, of capacities to put the agent in touch with reality and thus to bring into view previously unpossessed epistemic reasons. By contrast, belief is an exercise of an epistemic rational capacity to respond to possessed epistemic reasons.

For instance, I hear my mother tell me that my parents will come visit me this weekend, and later remember that she told me. These presentational attitudes are not themselves responses to reasons in my possession, and undergoing these attitudes does not consist in consciously adapting my outlook on the world to accord with reasons I possess. Rather, they are basic ways I have of picking up on facts that are epistemic reasons for me to form certain beliefs. My belief that my parents will come to visit me this weekend, on the other hand, is a manifestation of my epistemic rational capacity to respond appropriately to reasons I possess in having the relevant experiences and memories, viz. by forming the corresponding belief. I hasten to emphasize that my claim is not that I can adopt certain beliefs at will, but rather that I am rationally required to adapt my beliefs to the

25 Part of the reasoning behind this might be: Often enough, implicit biases lead to true beliefs. So, they are able to provide epistemic justification even on the occasions where things go wrong.

26 Thanks to Alex Byrne for raising this problem. 
facts as they present themselves to me, and that my beliefs are in that sense under my control. Again, my experiences and memories are not under my control in this way, and I am not responsible or criticizable, from an epistemic standpoint, for what I experience or remember.

But even though the PANINIs are not under my control, they are still rational responses to epistemic reasons, as they are exercises of my epistemic rational capacity to be in touch with reality, my most fundamental way of bringing epistemic reasons into my possession. It is through them that I am able to form beliefs as rational responses to possessed epistemic reasons and that my beliefs are rationally constrained by the facts. They are geared towards knowledge and part of the activity of attaining knowledge. Our epistemic rational capacities to get the facts into our possession as epistemic reasons are successfully exercised or manifested - they perform their role in our epistemic lives - only in cases in which we actually manage to pick up on facts. We can think of hallucinations or mistaken memories as failed exercises of that same rational capacity (Schellenberg 2015 ) and allow that they are still ways of possessing reasons. For, plausibly, our capacities to pick up on facts as epistemic reasons are fallible capacities. (Cf. McDowell 2011.) ${ }^{27}$

But what distinguishes the PANINIs and belief from implicit biases and implicit attitudes more generally? First, it is hard to see how occurrences of the latter could be exercises of epistemic rational capacities at all. Assume that implicit attitudes are presentational attitudes with a mind-toworld direction of fit. Further, assume that their content doesn't take the shape of universal statements - such as no women are well-suited to be professors. (If they did, they would almost always be false, and it would therefore be problematic to think of them as manifestations of an epistemic rational capacity.) Instead, they involve generalizations, for instance women generally are not well-suited to be professors, thus allowing for exceptions. Even given all this, implicit attitudes are still not epistemically rational dispositions. ${ }^{28}$

To begin with, they blind the believer to the individual case that she is confronted with. As illustrated by the fact that the very same application tends to be assessed as worse when its author is female, and as better when its author is male, implicit biases prevent subjects from taking into account relevant features of the particular individual they are trying to evaluate. Subjects are led to adopt beliefs about the particular instance that conform with what their implicit biases purport to be generally the case, despite the presence of counterevidence, such as the positive features of a particular woman's application. Contrast this with generalizations explicitly believed. For instance,

27 Elsewhere, I defend a version of epistemological disjunctivism which is compatible with my claims here about possession of epistemic reasons. (See Schmidt (forthcoming).) My view has an advantage over Williamson's (2000) view (that only known propositions count as possessed evidence/reasons) in that it is more liberal. So for instance, it can do some justice to the intuition behind the new evil demon problem.

28 I take it that implicit attitudes are dispositions that are activated, or become occurrent, in relevant situations. 
my belief that smoke generally means fire allows me to take into account the individual case I am confronted with. If I see that this particular smoke is not caused by a fire, but by a smoke machine, I'll be able to believe just this and to treat this particular smoke as an exception to the generalization. It is extremely difficult to do the same with individual cases which do not fit one's implicit bias.

Moreover, if I realize that an explicitly believed generalization is false, I can simply revise it, e.g. adopt the belief that smoke doesn't generally mean fire. This is nearly impossible for implicit bias. Since implicit attitudes are extremely stable, subjects cannot easily revise them as they can revise beliefs in the light of counterevidence. Even when a subject becomes aware that she has a mistaken implicit bias, she will typically be unable to simply abandon it and adopt a contrary implicit attitude. $^{29}$ Now it is true that the same goes for the PANINIs, which also resist revision. But what makes implicit attitudes much more problematic than PANINIs is that it is extremely difficult to insulate our belief and behavior-guiding systems against them. When a subject realizes that a PANINI is deceptive, she can simply stop taking it into account and thus insulate her beliefs and behavior from it. For instance, when she realizes that her experience as of a pink pig in front of her is a hallucination, she will give up her belief that there is a pig in front of her and adjust her behavior, even as the hallucination lingers. By contrast, subjects are virtually incapable of curbing the influence of their implicit biases - think of the fact that a subject's explicit egalitarian beliefs and her biased automatic evaluations and behavior can come into conflict, even when she is aware of and appalled by her implicit bias. ${ }^{30}$

So, implicit biases - and implicit attitudes more generally - blind believers to the individual case and thus are not good guides to true belief about particular cases. Moreover, even if a subject realizes that a particular implicit attitude is false, she is unable to adjust her cognitive stance to match the facts. She can neither revise her mistaken implicit attitude nor insulate her belief and behavior-guiding systems from it. Overall, then, it seems that her sensitivity to epistemic reasons, and thus her epistemic rationality, is systematically reduced by her implicit attitudes, and

29 Cf. Lai et al. (2016) for a very discouraging study regarding our ability to overcome implicit biases.

30 For detailed discussion, see Holroyd (2012). She points to evidence that conscious attempts to control the effects of implicit bias on behavior may even increase its influence, but argues in the end that if we commit ourselves to nonprejudiced behavior for its own sake, we may reduce its influence.

Feasible strategies to insulate our belief and behavior-guiding systems from the influence of implicit bias are typically indirect: For instance, the activation of relevant implicit biases can be prevented by requiring anonymized applications for a position. 
particularly her implicit biases. So, we shouldn't think of them as (exercises of) epistemic rational capacities. $^{31}$

Second, as argued above, basic ways of possessing epistemic reasons need to be available for deliberation, which implicit attitudes are not. When I describe my most basic ways of possessing reasons, I ascribe certain mental states or capacities to myself based on introspection alone: I believe that $p$ because I remember, I see, I intuit that $p .^{32}$ But, just going by introspection, I cannot talk about believing that $p$ because I have an implicit bias that $p$. Introspectively, beliefs based on implicit biases appear to be based on one of the other faculties that I am introspectively aware of as informing my beliefs. So, as far as our deliberative phenomenology and practices go, we cannot use implicit biases as our most fundamental ways of possessing epistemic reasons - we're not even introspectively aware that we have them. Overall, then, we are unable to form beliefs on the basis of implicit biases as a way of manifesting our ability to respond rationally to possessed reasons.

Here's a final analogy to support my claim that beliefs, PANINIs, and implicit biases can be distinguished in the way I have suggested. Compare the activity of attaining knowledge to playing a card game like poker. Think of a player's picking up her particular cards as analogous to the subject's undergoing certain PANINIs, and of her playing her cards as analogous to the subject's forming certain beliefs in response to epistemic reasons she possesses. Both picking up the cards and playing them are parts of the game governed by the rules of poker. Analogously, both undergoing basic presentational states and forming beliefs in response to them are part of the activity of attaining knowledge, and they are governed by epistemic rationality and are exercises of rational capacities. Now imagine that the player is handed an illegal card - for instance that she

31 This leaves it open that implicit biases are rational from an evolutionary standpoint, as competences to deal quickly with new, demanding situations.

The response that Sylvan \& Sosa might give to the implicit bias problem cannot differ much from mine. Just like me, they will have to argue that implicit biases are not epistemically competent attractions to assent, and do not manifest epistemic abilities or virtues. (Cf. Sosa 2007, 61.)

32 I concede that we don't have perfect introspective access to our PANINIs. It may happen that I hear a faint creak in the floorboards, which causes me to believe that someone is standing right behind me. But since I wasn't paying attention to my auditory perception, instead of properly introspecting my way of possessing a reason for my belief, I merely think that I can somehow sense that someone is staring at me from behind. In response, note that the fallibility of our capacity to introspect PANINIs doesn't undermine my point that we are generally in a position to use reasons we possess via PANINIs in deliberation because they are introspectively available to us. Moreover, the more difficult it is for the subject to determine in which way she possesses a reason, and even worse, whether she possesses any reason for her belief, the more we should worry about whether she has a reason for her belief at all. At some point, she will be in the situation that it is completely up in the air, from her perspective, whether it is rational for her to believe one way or another, so that plausibly, she does not possess a reason. 
unwittingly picks up an ace that is not part of the deck used in the game. Plausibly, picking up the card and playing it are not legal moves of the game - one cannot win a game of poker by using illegal cards. Analogously, drawing on an implicit bias is not a move in the activity of attaining knowledge, that is, not an exercise of an epistemic rational capacity and not governed by epistemic rationality. The beliefs that the subject forms in reaction to her biases are therefore not ways of possessing epistemic reasons. (Note that this analogy also backs the plausible claim that when implicit biases directly influence PANINIs, i.e. cognitively penetrate them, the latter are not exercises of a rational capacity to pick up epistemic reasons either. Imagine that Sam's visual experience of the applications is cognitively penetrated by his bias against women in academia. It will then not be a basic way of possessing an epistemic reason because it is contaminated by an epistemically irrational dispositon.)

To sum up, then, my reasons-first view can overcome the epistemic significance problem and the implicit bias problem by pointing out that there are fundamental ways of possessing reasons that the superblindsighter lacks, which are to be distinguished from implicit biases since they are exercises of epistemic rational capacities. So let me add a third claim to my view:

(Rational Capacities) PANINIs are exercises of epistemic rational capacities to pick up unpossessed epistemic reasons. Beliefs are exercises of epistemic rational capacities to respond appropriately to possessed epistemic reasons.

\section{Summing up}

I have defended a reasons-first view about epistemic justification, which appeals to basic ways of possessing reasons with the help of presentational attitudes that are not themselves in need of justification (PANINIs), against three objections: The objections that such a view cannot avoid being circular, that it cannot do justice to the epistemic significance of experience, and that it has to allow that beliefs based on implicit biases are justified.

An appeal to epistemic rational capacities - agents' abilities to respond to facts as epistemic reasons - has played a major role in my defense. So let me conclude my paper with a final statement about why this is still a reasons-first view, rather than a virtue-epistemological abilities-first view. Sylvan and Sosa (forthcoming) argue that epistemic virtues are normative bedrock in epistemology, for we need them to make sense of how we can possess epistemic reasons. By contrast, I think that, in individuating the rational capacities needed to possess epistemic reasons, reasons still come first. For what makes them the particular capacities that they are are the epistemic reasons that they are abilities to respond to. They are our abilities to become aware of which beliefs are favored by these reasons. Even stronger, what makes them intelligible as epistemic rational capacities at all (rather 
than just run-of-the-mill capacities, or some other rational capacities) is that they are capacities to respond appropriately to epistemic reasons.

\section{References}

G. E. M. Anscombe (1963). Intention. Cambridge, MA: Harvard University Press.

Bob Beddor (2015). "Evidentialism, Circularity, and Grounding." Philosophical Studies 172: 18471868.

----- (2016) Reduction in Epistemology. Dissertation.

Ned Block (1995). “On a Confusion about a Function of Consciousness.” Brain and Behavioral Sciences 18, 227-247.

Laurence BonJour (1980). "Externalist Theories of Empirical Knowledge." Midwest Studies in Philosophy 5: 53-73.

Alex Byrne (2016). “The Epistemic Significance of Experience.” Philosophical Studies 173: 947967.

Jonathan Dancy (2004). Ethics Without Principles. Oxford: Oxford University Press.

Tamar Szabo Gendler (2008). “Alief and Belief.” Journal of Philosophy 105: 634-663.

Jules Holroyd (2012). “Responsibility for Implicit Bias.” Journal of Social Philosophy 43: 274-306. Alvin Goldman (2011). "Toward a Synthesis of Reliabilism and Evidentialism?" Evidentialism and its Discontents. New York: Oxford University Press ed. Trent Dougherty, 254-820.

Hilary Kornblith (2015). "The Role of Reasons in Epistemology.” Episteme 12: 225-239.

Calvin Lai et al. (2016). "Reducing Implicit Racial Preferences: II. Intervention Effectiveness Across Time.” Journal of Experimental Psychology: General 145: 1001-1016.

John McDowell (2011). Perception as a Capacity for Knowledge. Milwaukee: Marquette University Press.

Eva Schmidt (2017). "New trouble for reasons as evidence: Means that don't justify the ends." Ethics 127: 708-718.

Eva Schmidt (forthcoming). "Subjective normative reasons for mentalism.” Epistemic realism and antirealism: Approaches to metaepistemology. London: Palgrave, eds. Christos Kyriacou \& Robin McKenna.

Eva Schmidt (n.d.). "Seeing isn’t believing: An argument for reasons-first epistemology." Mark Schroeder (2008). “Having Reasons.” Philosophical Studies 139: 57-71.

------ (2011). “What Does It Take to 'Have' a Reason?” Reasons for Belief. Cambridge: Cambridge University Press, eds. Andrew Reisner \& Asbjørn Steglich-Petersen, 201-22. 
Susanna Schellenberg (2016). "Phenomenal Evidence and Factive Evidence." Philosophical Studies 173: 875-896.

Susanna Siegel (2013) “Can Selection Effects on Experience Influence its Rational Role?” Oxford Studies in Epistemology, Vol. 4, ed. Tamar Gendler, Oxford: Oxford University Press, 240-270.

Ernest Sosa (2007), A Virtue Epistemology: Apt Belief and Reflective Knowledge, Vol. II, Oxford: Clarendon Press.

Rhea Steinpreis et al. (1999). "The Impact of Gender on the Review of the Curricula Vitae of Job Applicants and Tenure Candidates: A National Empirical Study.” Sex Roles 41: 509-528.

Kurt Sylvan \& Ernest Sosa (forthcoming). "The Place of Reasons in Epistemology." The Oxford Handbook of Reasons and Normativity, ed. Daniel Star, Oxford: Oxford University Press. Timothy Williamson (2000). Knowledge and Its Limits. Oxford: Oxford University Press. 